\title{
AS PESQUISAS SOBRE PROFESSORES INICIANTES NO BRASIL: UMA REVISÃO
}

\section{RESEARCH ABOUT BEGINNING TEACHERS IN BRAZIL: A REVIEW}

\author{
Priscila Monteiro Corrêa* \\ Vanessa Cristina Maximo Portella*
}

\begin{abstract}
Resumo: O campo da formação de professores vem ganhando cada vez mais destaque na produção acadêmica e o início da docência configura-se como uma temática ainda pouco explorada dentro desse campo maior (MARIANO, 2006A; PAPI; MARTINS, 2010). O objetivo do trabalho é contribuir para a sistematização/organização da atual produção do conhecimento sobre professores iniciantes no Brasil, a partir da síntese de Papi e Martins (2010), levantando e problematizando questões que emergem dos estudos sobre essa temática. O corpus do artigo é constituído pelos trabalhos apresentados nas reuniões anuais da ANPED nos anos de 2008, 2009, 2010 e 2011 e pelos trabalhos registrados no banco de teses da CAPES nos anos de 2008, 2009 e 2010. Na conclusão são apresentadas algumas iniciativas brasileiras destinadas à etapa de iniciação à docência e retomadas algumas evidências que emergiram da revisão realizada, tais como a importância de realizar pesquisas sobre o assunto nas diferentes regiões do país e de considerar nas pesquisas o trabalho também com professores que exercem seu ofício em diferentes tipos de escola. Os achados do trabalho reiteram as sínteses anteriores no sentido de mostrar a importância da continuidade dos investimentos em pesquisas sobre o início da docência.
\end{abstract}

Palavras-chave: Professores iniciantes. Produção acadêmica. Iniciação à docência. Formação de professores. Desenvolvimento profissional.

Abstract: Studies about teacher education are becoming more prominent in the academic production, although the first years of teaching is a theme not fully explored within the broader teacher education agenda (Mariano, 2006a; Papi e Martins, 2010). The purpose of this paper is to contribute to standardize/ organize current knowledge on Brazilian beginning teachers through the analysis developed by Papi and Martins (2010). The corpus about the early years of teaching are based on the ANPEd 2008, 2009, 2010 and 2011 proceedings as well as on the CAPES 2008, 2009, 2010 database. The conclusion presents some Brazilian initiatives concerning the early years of teaching. The paper also presents some evidence based on the review, such as the relevance of developing research about the topic in the different regions of the country. In addition, this paper reinforces that research should consider the work of teachers who act in different types of schools. The findings emphasize previous considerations regarding the relevance of continuous research about the early years of teaching.

Keywords: Beginning teachers. Academic production. Early Years of Teaching. Teacher education. Professional development.

\footnotetext{
* Mestre em Educação pela UFRJ e doutoranda em Educação PUCRJ. E-mail: <pripricorrea@gmail.com>. Master in Education from UFRJ and doctoral student in Education from PUCRJ. E-mail: <pripricorrea@gmail.com>.

** Mestre em Educação pela PUCRJ e doutoranda na mesma instituição. Professora do Colégio Pedro II. E-mail: <vanessacmportella@gmail.com>.

Master in Education from PUCRJ and doctoral student from PUCRJ. Teacher at Pedro II School.

E-mail: <vanessacmportella@gmail.com>.
} 
O campo da formação de professores vem ganhando cada vez mais destaque na produção acadêmica e o início da docência configura-se, no Brasil, como uma temática ainda pouco explorada dentro desse campo maior.

A formação de professores é um processo contínuo, sem um fim estabelecido $a$ priori, do qual fazem parte a experiência acumulada durante a passagem pela escola enquanto estudante; a formação profissional específica - que tem sido denominada formação inicial -; a iniciação na carreira e a passagem de estudante a professor, iniciada já durante o processo de formação inicial, por meio da realização de atividades de estágio e prática de ensino; e a formação contínua.

No caminho do desenvolvimento profissional do professor, Marcelo (2009) chama a atenção para esse conceito, destacando-o no contexto de uma construção que se faz ao longo de toda a carreira docente, na constituição do eu profissional. Destaca a opção pelo conceito de desenvolvimento profissional em detrimento de outras noções, tais como as de formação em serviço, formação permanente ou contínua, também utilizadas em nosso contexto, porque entende que o conceito de desenvolvimento profissional dá mais precisamente a ideia de continuidade e supera a tradicional distinção entre formação inicial e contínua de professores (MARCELO, 2009, p.9). Assim, baseado em autores que realizaram revisões e sínteses a respeito dessa ideia, Marcelo (idem) enfatiza que está a emergir uma nova perspectiva de desenvolvimento profissional, que se constitui de diferentes oportunidades e experiências formativas, planejadas sistematicamente e que se realizam a longo prazo, a fim de promover um crescimento profissional docente. Algumas características emergentes dessa concepção são: o professor se faz atuante no processo como sujeito que aprende de forma ativa; o processo tem lugar em contextos concretos, preferencialmente, onde o professor exerce as suas atividades de docência, de modo que este possa fazer relações entre suas experiências formativas e sua experiência prática; o desenvolvimento profissional é colaborativo, ainda que haja espaço para reflexões e trabalhos individuais; não existe uma única forma de desenvolvimento profissional, podendo este assumir formatos diferentes em diferentes contextos de modo a atender às diversificadas demandas (MARCELO, 2009). Ao que notamos, o desenvolvimento profissional vai se dando por meio de ações intencionais e "à medida que os docentes ganham experiência, sabedoria e consciência profissional” (MARCELO, 2009, p.11). Os anos de experiência, por si só, não bastam para promover desenvolvimento profissional.

A literatura sobre professores principiantes aponta que os primeiros anos de exercício profissional se configuram como uma etapa marcante na vida do professor e que o início da docência é uma das etapas do seu processo de formação, diferenciada das demais. Segundo Marcelo (1999), é na "fase de iniciação", que corresponde aos primeiros anos de experiência docente, que os docentes fazem a "transição" de estudantes para professores e precisam adquirir conhecimentos profissionais, bem como manter um equilíbrio pessoal. Esse período pode ser mais fácil ou mais difícil,

dependendo das condições encontradas pelos professores no local de trabalho, das relações mais ou menos favoráveis que estabelecem com outros colegas, bem como da formação que vivenciam e do apoio que recebem nessa etapa do desenvolvimento profissional. (PAPI e MARTINS, 2010, p. 43). 
Esse também é o período de choque da realidade (VEENMAN, 1988), quando o professor se depara com a diferença entre o idealizado nos cursos de formação e o encontrado na realidade cotidiana das escolas.

Pesquisas sobre formação de professores, especialmente sobre iniciantes, em diversos países - Marcelo (1999, 2011); Mariano (2006b); Papi e Martins (2010) - apontam a necessidade de se considerar o início da docência como uma fase diferenciada, com características e necessidades próprias, que demanda apoio e formação específicos.

O objetivo deste artigo é contribuir para a sistematização/organização da atual produção de conhecimento sobre professores iniciantes no Brasil. A estratégia metodológica adotada foi tomar como referência a síntese temática de Papi e Martins (2010) e, a partir dela, levantar e problematizar algumas questões que emergem dos estudos sobre o início da docência no Brasil. O corpus eleito para esta pesquisa foi composto pelos trabalhos apresentados nas reuniões anuais da ANPED nos anos de 2008, 2009, 2010 e 2011 e pelos trabalhos registrados no Banco de Teses da CAPES nos anos de 2008, 2009 e $2010^{1}$.

A seguir, são apresentados os resultados da pesquisa realizada na página on-line da ANPED, seguida dos resultados da pesquisa realizada no Banco de Teses da CAPES. Por fim, a título de considerações finais, são apontadas algumas iniciativas brasileiras destinadas à etapa de iniciação à docência e retomadas algumas evidências que emergiram da pesquisa realizada.

\footnotetext{
${ }^{1}$ Os trabalhos produzidos nos anos de 2011 e 2012 ainda não foram registrados no Banco de Teses da CAPES, disponível em: <http://capesdw.capes.gov.br/ capesdw/>. Acesso em: 06 abr. 2012.
}

\section{Questões emergentes nas pesquisas apresentadas nas reuniões anuais da ANPED}

Utilizando os mesmos critérios de Papi e Martins (2010), foi feito um levantamento por meio dos títulos (professores iniciantes, entrada na docência, inserção na carreira $^{2}$ ) disponíveis na página on-line da ANPED, das pesquisas (trabalhos e pôsteres) sobre o tema professores iniciantes, apresen-

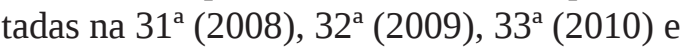
$34^{\mathrm{a}}$ (2011) reuniões, nos GT 4 (Didática), 8 (Formação de Professores) e 14 (Sociologia da Educação). A partir desse levantamento, foi feita a leitura dos textos das pesquisas selecionadas, buscando identificar as atuais questões que emergem das pesquisas realizadas no país sobre os professores iniciantes e estabelecer um diálogo com sínteses anteriores: Papi e Martins (2010), Mariano (2006a, 2005) e Lima (2004).

\footnotetext{
${ }^{2}$ Apesar da expressão "inserção na carreira” remeter à ideia de entrada na carreira docente, no trabalho intitulado "Professores na Educação Infantil: inserção na carreira, espaço de atuação e formação", de Valdete Côco (UFES), a autora refere-se à inserção na carreira de todos os profissionais atuantes nas atividades pedagógicas da Educação Infantil, distanciandose, portanto, do foco deste trabalho - o professor iniciante -, o que fez com que esse trabalho não fosse considerado nas análises.
} 
Quadro $^{3} 1$ - Pesquisa por no de trabalhos/GT/ano

\begin{tabular}{|c|c|c|c|c|c|c|}
\hline \multirow{2}{*}{ ANO } & \multicolumn{2}{|c|}{$\begin{array}{c}\text { GT 04 } \\
\text { Didática }\end{array}$} & \multicolumn{2}{c|}{$\begin{array}{c}\text { GT 08 } \\
\text { Formação de Professores }\end{array}$} & \multicolumn{2}{c|}{ Gociologia da Educação } \\
\hline & Número de trabalhos & \multicolumn{2}{c|}{ Número de trabalhos } & \multicolumn{2}{c|}{ Número de trabalhos } \\
\cline { 2 - 7 } & Total & $\begin{array}{c}\text { Sobre } \\
\text { Professores } \\
\text { Iniciantes }\end{array}$ & Total & $\begin{array}{c}\text { Sobre Professores } \\
\text { Iniciantes }\end{array}$ & Total & $\begin{array}{c}\text { Sobre } \\
\text { Professores } \\
\text { Iniciantes }\end{array}$ \\
\hline $\mathbf{2 0 1 1}$ & 16 & 0 & 22 & 2 & 17 & 0 \\
\hline $\mathbf{2 0 1 0}$ & 13 & 1 & 17 & 1 & 13 & 0 \\
\hline $\mathbf{2 0 0 9}$ & 13 & 0 & 18 & 0 & 14 & 0 \\
\hline $\mathbf{2 0 0 8}$ & 20 & 0 & 21 & 0 & 14 & 0 \\
\hline TOTAL & 62 & 1 & 78 & 3 & 58 & 0 \\
\hline
\end{tabular}

O quadro anterior mostra que, de um total de 198 trabalhos apresentados nos três GTs nos últimos quatro anos, apenas 4 tiveram como foco os professores iniciantes. Esse baixíssimo número de trabalhos encontrados na pesquisa reitera as conclusões apresentadas anteriormente nos estudos de Papi e Martins (2010), Mariano (2005) e Lima (2004): embora seja uma fase importante para a constituição da docência e desenvolvimento profissional do professor, ainda hoje, o professor iniciante e o início de sua carreira têm merecido pouca atenção por parte dos pesquisadores brasileiros.

No que diz respeito ao teor das pesquisas, dois trabalhos - Cunha (2010) e Isaia, Maciel e Bolzan (2010) - trataram do início da docência universitária, apontando principalmente para a falta de formação (inicial e continuada) para a atuação do professor no Ensino Superior; um trabalho - Papi (2011) - tratou do desenvolvimento profissional de professoras iniciantes bem-sucedidas e um trabalho - Ribeiro, Ambrosetti e Teixeira (2011) - tratou do PIBID, Programa de Bolsa de Iniciação à Docência, experiência de iniciação à docência ainda no período de formação inicial.

\footnotetext{
${ }^{3}$ Os quadros do artigo foram elaborados pelas autoras.
}

Cunha (2010) e Isaia, Maciel e Bolzan (2010) percorreram caminhos distintos - a primeira baseou-se em pesquisa bibliográfica e as últimas em pesquisa empírica - na investigação sobre o início da docência universitária para chegarem às mesmas conclusões: falta qualificação para atuar no Ensino Superior, uma vez que o domínio do campo específico de conhecimento não credencia o candidato a professor a exercer a docência, e que é falso o pressuposto de que a pesquisa qualifica para o ensino; falta também formação pedagógica, ética e humana, inerentes à profissão docente, já que a preparação que tiveram não responde às exigências da docência e que os professores não foram para ela preparados, o que os torna profissionalmente frágeis, assumindo um papel para o qual não possuem saberes sistematizados. Assim sendo, partindo do pressuposto de que a docência é um processo construído ao longo da carreira, os professores iniciantes terão de construir seu aparato profissional,

isto é, definir estilos de docência em ação, revelando valores e posições políticas e éticas. Atuarão definindo padrões de conduta e construirão uma representação de autoridade que se quer dialógica e legitimada. (CUNHA, 2001, p. 2). 
Cunha (2011) traz uma importante contribuição fazendo a análise dos estudos apresentados no II Congreso Internacional sobre Profesorado Principiante e Inserción Profesional a la Docencia, ocorrido em Buenos Aires, Argentina, entre 24 e 26 de fevereiro de 2010, no que diz respeito à natureza e intensidade dos estudos sobre professores iniciantes, construindo uma reflexão sobre os temas e suas incidências, com o objetivo de explicitar tendências e mostrar a pujança e diversidade de abordagens que compõem o mosaico de interesses e preocupações em torno do tema.

Destaca-se, nessa análise, o fato de que as experiências de acompanhamento $e$ formação de professores iniciantes aparecem em primeiro lugar entre os trabalhos apresentados, "evidenciando que o processo de inserção profissional dos professores não é uma responsabilidade individual, mas um desafio institucional das políticas públicas” (CUNHA, 2010, p. 4). A autora constatou que o investimento institucional vem sendo reconhecido como importante em muitos países e em grupos acadêmicos, levando-os a lançar mão dos chamados docentes mentores ou tutores - professores mais experientes orientando docentes iniciantes em todos os níveis de ensino, da educação infantil à universidade -, bem como oferecendo oficinas e cursos aos docentes em fase inicial de carreira, formando grupos cooperativos, que problematizam a condição inicial dos principiantes e diminuem as possibilidades de frustrações.

O trabalho de Papi (2011), por sua vez, voltou-se para duas professoras iniciantes bem-sucedidas do Ensino Fundamental na rede pública municipal, tomando como foco seu desenvolvimento profissional. A au- tora constata que "é de responsabilidade da escola o apoio e acompanhamento do trabalho dos professores iniciantes na rede municipal, embora a literatura aponte a relevância de programas específicos de iniciação para favorecer o desenvolvimento profissional" (PAPI, 2011, p.12) e propõe como alternativa, na inexistência de uma proposta melhor definida, que as professoras mais experientes passem a auxiliar as iniciantes no seu desenvolvimento profissional quanto aos desafios enfrentados em sua prática pedagógica, estratégias semelhantes às de tutoria / mentoria / grupos cooperativos, valorizadas no trabalho de Cunha (2010).

Já o trabalho de Ribeiro, Ambrosetti e Teixeira (2011) traz a contribuição de avaliar o PIBID a partir da experiência de um grupo de alunas do curso de Pedagogia, que avaliou o significado da participação no programa e seu impacto na própria formação. As alunas destacaram que a participação no PIBID vem significando para elas uma experiência de inserção profissional e de identificação com a docência, uma vez que têm a possibilidade de participar ativamente do trabalho nas escolas, construindo sua vida profissional.

Essas análises evidenciaram que os debates acadêmicos sobre os professores iniciantes ainda têm um longo caminho a percorrer. A partir da pesquisa realizada e de outras sínteses, especialmente as de Mariano (2005, 2006a), propõe-se como possíveis alternativas para esse avanço que sejam considerados nas pesquisas os diferentes níveis de ensino.

Observou-se também a necessidade de que sejam levadas em consideração nas pesquisas também instituições privadas, pois o trabalho dos professores iniciantes

Olhar de professor, Ponta Grossa, 15(2): 223-236, 2012. Disponível em <http://www.uepg.br/olhardeprofessor> 
nas escolas públicas e privadas é consideravelmente diferente e acredita-se que o contraponto entre ambas ajuda a compreender melhor cada uma.

Por fim, aposta-se na realização de pesquisas que abordem o início da docência de forma positiva. Segundo Mariano (2005), a maioria dos trabalhos analisados por ele investigava aspectos negativos desse período, como os sentimentos de solidão, isolamento e insegurança para atuar na profissão, bem como as dificuldades enfrentadas. Faltam trabalhos como o de Papi (2011), que ponham em foco os professores iniciantes bem-sucedidos e/ou propostas para facilitar a inserção e o desenvolvimento profissional do professor iniciante.

Quadro 2 - Pesquisa por assunto/expressão exata

\begin{tabular}{|c|c|c|c|}
\hline ANO & $\begin{array}{c}\text { MESTRADO E } \\
\text { DOUTORADO } \\
\text { ASSUNTO } \\
\text { Professores Iniciantes }\end{array}$ & $\begin{array}{c}\text { MESTRADO E } \\
\text { DOUTORADO } \\
\text { ASSUNTO } \\
\text { Iniciação Profissional }\end{array}$ & $\begin{array}{c}\text { MESTRADO E } \\
\text { DOUTORADO } \\
\text { ASSUNTO } \\
\text { Iniciação à Docência }\end{array}$ \\
\hline $\mathbf{2 0 1 0}$ & 09 & 01 (já referido) & $\begin{array}{c}03 \\
\text { (e mais } 1 \text { já referido }{ }^{5}\end{array}$ \\
\hline $\mathbf{2 0 0 9}$ & 08 & 0 & $\begin{array}{c}02 \text { (e outros } 3 \\
\text { já referidos) }\end{array}$ \\
\hline $\mathbf{2 0 0 8}$ & 07 & 01 (já referido) & $\begin{array}{c}02 \text { (e outros } 4 \\
\text { já referidos) }\end{array}$ \\
\hline TOTAL & 24 & 0 & 7 \\
\hline
\end{tabular}

Como mostra o quadro, os trabalhos perfazem um total de 31 pesquisas, distribuídas nos anos de 2008, 2009 e 2010, apresentando um número um pouco maior em 2010.

Em uma divisão mais geral dos trabalhos, por temáticas, de acordo com os títulos e leitura dos resumos, eles foram divididos em três grupos: no primeiro, foram considerados os trabalhos ligados à formação inicial; no segundo, trabalhos que analisam diversas questões sobre a prática pedagógica

\section{Questões emergentes nas pesquisas que integram o Banco de Teses da CAPES}

No que se refere ao Banco de Teses da CAPES, como já dito, a pesquisa foi baseada nos anos subsequentes aos analisados por Papi e Martins (2010) e, para a busca e agrupamento dos trabalhos, foram usados os mesmos critérios das referidas autoras. Foi feita, portanto, a busca por assunto no banco de teses, pelas expressões exatas "professores iniciantes", "iniciação profissional” e "iniciação à (a) docência". Na sequência, foi realizada a leitura e seleção dos títulos pertinentes e a leitura dos resumos. Dessa forma, chegou-se aos dados a serem apresentados a seguir . 
Quadro 3 - Número de trabalhos/temática

\begin{tabular}{|c|c|c|}
\hline $\begin{array}{c}\text { Formação } \\
\text { inicial }\end{array}$ & $\begin{array}{c}\text { Prática } \\
\text { pedagógica } \\
\text { do professor } \\
\text { iniciante }\end{array}$ & $\begin{array}{c}\text { Formação do } \\
\text { professor em } \\
\text { período de } \\
\text { iniciação }\end{array}$ \\
\hline 4 & 21 & 6 \\
\hline
\end{tabular}

No primeiro grupo, o que apresenta ligação direta com a formação inicial, foram encontrados trabalhos tratando do processo reflexivo-colaborativo na formação inicial de professores de português (língua materna); da prática reflexiva na formação inicial de professores de inglês; do estágio na formação como lugar de construção de saberes docentes e do aprender a ensinar matemática nas séries iniciais.

No segundo grupo, que analisa questões sobre a prática pedagógica e a inserção do iniciante no campo profissional, foram elencados trabalhos que tratam da socialização profissional; da prática pedagógica, saberes específicos e constituição de saberes no ensino da matemática; de dificuldades e superações nos primeiros anos de docência em matemática; da formação, prática pedagógica e utilização de materiais didáticos na concepção de professores iniciantes que ensinam matemática; da manifestação de saberes docentes na prática pedagógica de professores iniciantes e experientes de educação física; dos primeiros anos da docência no discurso de professores de inglês; da formação docente na área das ciências biológicas; das dificuldades, inserção no mercado de trabalho, competências e desafios de professores iniciantes no Ensino Superior; de vivências, saberes e conflitos de professores de química em início de carreira; da construção de saberes por docentes iniciantes de história; do processo de constituição de um professor pesquisador na área de edu- cação ambiental; das exigências do trabalho docente para além do tempo do ensino para professores iniciantes e experientes; da mobilização de saberes por professores que ensinam matemática; da constituição da vida profissional de professores de matemática; de dilemas e saberes da profissão nas histórias de vida de professores de língua portuguesa; de professores de língua inglesa em início de carreira e a produção da profissão docente e da aprendizagem da docência com foco na intermulticulturalidade.

Embora esse grupo seja o maior, tomou-se o cuidado de esclarecer que foram agrupados todos esses trabalhos porque suas temáticas se afinam e, portanto, torna-se difícil desmembrá-las. Entretanto, se tem ciência de que abordam questões bastante variadas e essa categorização foi tomada de modo bem geral.

No terceiro grupo, que se refere à formação de professores em período de iniciação, constam trabalhos sobre programas de mentoria para professores iniciantes; práticas de formação continuada no desenvolvimento profissional de professores iniciantes; desenvolvimento profissional de principiantes mediante grupo colaborativo de trabalho; experiências de ensino e aprendizagem como estratégia de formação on-line em programa de mentoria e pesquisa intervenção com professores universitários sem formação pedagógica.

No recorte feito, encontrou-se um número maior (o dobro) do que o encontrado por Papi e Martins (2010) de trabalhos que tratam da formação de iniciantes em início de carreira. Embora tenha apresentado movimento crescente, essa temática ainda é pouco tratada nos trabalhos sobre professores principiantes no Brasil. Isso se justifica em virtude de, entre nós, as iniciativas em torno de programas de inserção à docência serem 
ainda poucas e recentes. Como fica evidente em estudos nacionais (MARIANO, 2006b; PAPI; MARTINS, 2010) e internacionais (MARCELO, 1999; 2011), os professores iniciantes precisam de atendimento diferenciado e apoio na fase de iniciação profissional para atender a demandas específicas dessa etapa. E, nesse sentido, os programas de iniciação podem se apresentar como um caminho para a diminuição da evasão ainda nos primeiros anos da docência e como uma possibilidade na trajetória de desenvolvimento profissional de principiantes.

Como na pesquisa de Papi e Martins (2010), não foram encontrados trabalhos que relacionem professores iniciantes e sucesso escolar ou professores considerados bemsucedidos.

Diferentemente do que Mariano (2006b) ressalta no contingente de trabalhos por ele analisados, no corpus selecionado, não há quantidade um pouco maior de trabalhos em torno da temática da socialização profissional. Apenas 2 dos 31 se concentraram nesse aspecto. Encontrou-se um foco grande de pesquisas que tratam de professores de Matemática ou de professores que ensinam matemática nas séries iniciais.

No que se refere à filiação institucional, vê-se nítida concentração das pesquisas em torno da fase de iniciação da docência no estado de São Paulo. Dos 31 encontrados, 15 se vinculam a universidades desse estado; quatro a universidades do estado de Minas Gerais; três a uma universidade do Mato Grosso do Sul; dois a uma universidade do Maranhão; dois a universidades do Rio Grande do Sul; um a uma universidade do Sergipe; um a uma universidade do Mato Grosso; um a uma universidade da Bahia; um a uma universidade do Paraná; e um a uma universidade de Pernambuco. Esses dados coincidem com o trabalho de Mariano (2006b), quando o autor analisou, em sua dissertação, trabalhos apresentados no ENDIPE e na ANPED e constatou que 50\% da produção sobre docentes iniciantes, no período estudado, se concentrava no estado de São Paulo. Também convergem com os resultados de Papi e Martins (2010) que constataram na análise de 14 trabalhos sobre iniciantes apresentados nas $28^{\mathrm{a}}, 29^{\mathrm{a}}$ e $30^{\mathrm{a}}$ reuniões da ANPED, que 11 se vinculavam a instituições de São Paulo.

Uma tentativa de análise desse banco foi a de identificar a quantidade de trabalhos por nível de ensino. Tinha-se a intenção de mostrar em que nível os trabalhos sobre o início da docência se concentram ou se a distribuição é mais ou menos equilibrada entre eles. Embora seja possível ter clareza de que é na educação básica que se concentra a maior parte deles, não foi possível evidenciar isso numericamente, desdobrando a educação básica em suas etapas, pois vários trabalhos não esclareceram em seu resumo em que nível ou com professores de que segmento foram realizados. Para exemplificar, houve pesquisas que trabalharam com professores especialistas. Essa informação permite saber que as pesquisas foram realizadas no $2^{\circ}$ segmento do Ensino Fundamental ou no Ensino Médio, não mais do que isso.

Finalmente, vale destacar que no caminho da revisão realizada, algumas dificuldades foram encontradas e entendemos a relevância de esclarecê-las para que sirvam para nós, pesquisadores, sempre na busca de aperfeiçoarmos nossa prática de pesquisa. Uma delas é que alguns trabalhos encontrados não evidenciaram, com clareza, nem no título, nem no resumo, que estavam tratando de professores em início de carreira. Embora, por vezes, apresentassem algumas pistas que nos faziam supor que se tratava desta fase profissional, estas não eram suficientes para atestar que estavam trabalhando com o 
início da carreira docente. Quando isso ocorreu, optamos por não considerar os trabalhos por falta de elementos que nos dessem condições de incluí-los nos critérios tomados para esta análise.

\section{Considerações finais}

Para finalizar, julgamos pertinente apresentar algumas iniciativas brasileiras destinadas à etapa de iniciação à docência e retomar algumas evidências que emergiram da pesquisa realizada.

Quando se fala em "programas de iniciação” na área da educação, geralmente, faz-se referência a experiências formativas que visam a atender e dar suporte a professores nos seus primeiros anos de profissão, respeitando as especificidades dessa etapa profissional, marcada pelo isolamento, insegurança, dificuldade em estabelecer relações entre teoria e prática etc. As diferentes fases da vida profissional trazem consigo exigências de cunho pessoal, profissional, institucional e contextual diferenciadas e que, portanto, exigem estratégias formativas diferenciadas. Assim, os programas de iniciação têm propostas de auxiliar o professor a enfrentar de modo menos sofrido o choque da realidade (VEENMAN, 1988) e a fase de sobrevivência (HUBERMAN, 1992).

Huling-Austin (1986, 1990 apud MARCELO, 1999, p. 122) referindo-se aos objetivos de programas de iniciação, destaca alguns, que, evidentemente, não são os únicos:

Melhorar a acção docente; aumentar as possibilidades de permanência dos professores principiantes durante os anos de iniciação; promover o bem-estar pessoal e profissional dos professores principiantes; satisfazer os requisitos formais relativos à iniciação e à certificação; transmitir a cultura dos sistemas aos professores principiantes.

No cenário internacional, Papi e Martins (2010) destacam, com base em publicação da rede Eurydice (2002), que países como Áustria, Finlândia, Inglaterra, Espanha, Bélgica, País de Gales, Estônia, Hungria, Chipre, Grécia, Itália, Irlanda do Norte, Polônia já possuem iniciativas de apoio a professores principiantes e que países como Alemanha, Luxemburgo e Portugal iniciaram os debates a esse respeito.

Também Marcelo (2011), além de abordar programas de inserção profissional que estão acontecendo na Europa, destaca outros que estão em desenvolvimento em outras partes do mundo, a saber: Israel, Nova Zelândia, Japão, Shanghai, além dos Estados Unidos, que se caracterizam por possuir uma diversidade desses programas. Salienta que na América Latina começam a ser observadas algumas iniciativas nesse sentido, ainda em suas versões iniciais ou exploratórias.

Como foi possível observar na revisão feita por Cunha (2011), têm sido reconhecidos os investimentos institucionais feitos em programas de inserção à docência e estudos sobre estes programas já aparecem com ênfase quando é considerado o cenário internacional.

Ao focar no Brasil, são apresentadas a seguir algumas experiências que vêm se destacando nesse caminho.

De uma forma pontual, mas também no sentido de dar algum suporte aos que ingressam, Gatti, Barretto e André (2011), no estudo "Políticas docentes no Brasil: um estado da arte", sinalizam que a SEDU6/ES vem oferecendo formação de $60 \mathrm{~h}$, como uma das etapas de seleção em seus concursos,

\footnotetext{
${ }^{6}$ SEDU/ES - Secretaria de Educação do Estado do Espírito Santo
} 
seguidas de prova eliminatória. Também mostram que a SEDUC $7 / \mathrm{CE}$ fez uma modificação recente nos seus concursos. A terceira parte da seleção foi um curso de capacitação, desdobrada em cinco módulos, a saber:

1) introdução à educação a distância e ao uso de ambiente virtual de aprendizagem; 2) administração pública e direitos e deveres do servidor; 3) política educacional e legislação de educação básica; 4) didática geral; 5) didática aplicada a uma das seguintes áreas de conhecimento: arte-educação, biologia, educação física, filosofia, física, geografia, história, química, sociologia, línguas espanhola, inglesa e portuguesa. (GATTI; ANDRÉ; BARRETTO, 2011, p. 214).

Na SEMED ${ }^{8}$ de Jundiaí, os professores iniciantes recebem capacitação antes de entrar em sala de aula. Esta é remunerada, tem duração de 30 dias e é realizada por profissionais da Fundação Vanzolini ou da Bradesco. Conforme as próprias autoras destacam, essas iniciativas não são ideais, pois acontecem de modo pontual na entrada dos professores, sem que sejam seguidas de um acompanhamento dos docentes no decorrer de um período mais longo do seu trabalho.

As autoras (GATTI; ANDRÉ; BARRETTO, 2011) mostram que foram encontradas duas ações de maior duração voltadas especificamente para os iniciantes, uma na SEMED de Sobral (CE) e outra na SEMED de Campo Grande (MS). A SEMED de Sobral tem um programa de formação para os docentes em estágio probatório. O programa é uma experiência de formação com vistas ao aperfeiçoamento da prática pedagógica. Está regulamentado pela Lei Municipal nº71/2006. Durante os três anos de estágio probatório,

\footnotetext{
${ }^{7}$ SEDUC - Secretaria de Educação do Estado do Ceará
}

${ }^{8}$ SEMED - Secretaria Municipal de Educação os professores iniciantes participam, obrigatoriamente, das formações oferecidas pela Estapem. Uma vez que a SEMED de Sobral não autoriza a saída do professor de sala de aula para que ele participe da formação, esta é realizada uma vez por semana, à noite. Entretanto, os docentes recebem $25 \%$ do salário base de $40 \mathrm{~h}$ para participar da formação. Os encontros têm carga horária total de 200h e são assim divididos:

\begin{abstract}
encontros semanais com uma hora aula para trabalhar o Programa de modificabilidade cognitiva e aprendizagem mediada; dois encontros mensais voltados ao trabalho na escola, sob a forma de seminários de estudo e discussão de matemática e língua portuguesa; e ampliação do universo cultural, desenvolvida com a participação dos professores nas atividades do Programa Olhares. (GATTI; ANDRÉ; BARRETTO, 2011, p. 215).
\end{abstract}

Na SEMED de Campo Grande, o programa pretende contextualizar e inserir o principiante na política de educação de qualidade adotada pela secretaria e suprir lacunas da formação inicial. Os investimentos do programa são organizados em cinco momentos. O primeiro destinase ao conhecimento do funcionamento do sistema de ensino, documentos e políticas que servirão de base para a sua atuação profissional. Nessa etapa, os professores são informados sobre as funções de cada setor da secretaria e da escola. No segundo momento, em encontro com os professores, tem-se a intenção de descobrir suas dificuldades e organizar as formações. No terceiro, os encontros formativos acontecem principalmente nas escolas e de maneira coletiva. O grupo responsável pela formação de determinada escola vai até o local e realiza as atividades com os professores, solicitando também a presença da equipe pedagógica e do diretor adjunto, 
para que estes tenham condições de dar continuidade ao trabalho de formação na escola. São atendidos, especialmente, os professores que atuam na Educação Infantil, primeiro, segundo e terceiro anos do Ensino Fundamental, porque é nesses anos que se concentra uma parcela maior de iniciantes. O quarto se dá pelo acompanhamento do processo de ensino e aprendizagem, com proposição de alternativas para auxiliar o trabalho dos iniciantes. Nesse processo são utilizadas várias estratégias para a coleta de dados e informações sobre o modo como se organiza o processo de alfabetização nas unidades escolares. E, por fim, o quinto momento consiste em fazer uma avaliação diagnóstica da aprendizagem dos alunos, principalmente dos três primeiros anos do Ensino Fundamental. Os resultados dessa avaliação fazem parte dos instrumentos de validação, ou não, do trabalho de formação que a secretaria realiza.

Outra iniciativa em desenvolvimento que está no caminho de um programa de iniciação é o Programa de Residência Docente no Colégio Pedro II. Fruto de uma iniciativa da CAPES, como proposta de desenvolver um programa de iniciação que complemente a formação inicial de professores em início de carreira e auxilie o desenvolvimento profissional desses, o Colégio Pedro II foi escolhido como campo para a implementação de um programa de residência docente, devendo-se isso ao seu trabalho pedagógico já bastante consolidado, com resultados importantes no que se refere à qualidade de ensino.

A partir de um acordo feito entre as partes, uma equipe do Colégio Pedro II, coordenada pela Diretoria de Pós-Graduação e Pesquisa, começou a pensar em como poderia ser estruturado o programa de residência dentro do colégio. E tendo a sua proposta submetida à CAPES aprovada ainda em 2011, começou em 2012 a efetivação do processo.
Consta no documento elaborado pela equipe do Colégio Pedro II que o programa tem por objetivo "Aprimorar a formação do professor da educação básica, oferecendo um programa de formação continuada, através do desenvolvimento de competências docentes in loco [...]” (COLÉGIO PEDRO II, 2011, p. 1).

O Programa de Residência Docente (PRD) é destinado a professores com até três anos de conclusão do curso de Licenciatura Plena e que atuem em qualquer área disciplinar oferecida pelo Colégio Pedro II, desde o $1^{\circ}$ ano do Ensino Fundamental até o $3^{\circ}$ ano do Ensino Médio. E as vagas são oferecidas, preferencialmente, a professores da rede pública de ensino, redes estadual e municipal.

O PRD é uma pós-graduação lato sensu, cuja previsão de duração é de um ano, com carga horária de 500 horas, assim distribuídas: observação e colaboração na docência (65\% da carga total), formação continuada por meio de oficinas presenciais e semipresenciais (25\%) e observação em setores administrativo-pedagógicos (10\%). O programa conta com quatro categorias de participantes: o professor residente, o professor supervisor, o coordenador de área e o coordenador institucional. As vagas disponíveis em cada ano de realização do programa dependerão da demanda externa, da disponibilidade de atendimento do Colégio Pedro II e também do número de bolsas fornecidas pela CAPES, conforme consta no referido documento. Para o projeto piloto, que está em curso, a disponibilidade foi de dezessete professores supervisores, quatro coordenadores de área, um coordenador institucional e cinquenta professores residentes, estes pertencentes a outras redes de ensino. Cada participante do programa, residente, supervisor, coordenador de área e coordenador institucional, recebe uma bolsa da CAPES, com valor diferenciado de acordo com a sua 
categoria de participação. Cada professor supervisor pode ter até cinco residentes sob sua responsabilidade.

Desse primeiro grupo, participam como residentes professores iniciantes das redes estadual e municipal do Rio de Janeiro, indicados por sua respectiva rede para fazerem parte do programa. As demais categorias de participantes são preenchidas por professores experientes do próprio Colégio Pedro II. A ideia é que, para os próximos anos, seja lançado edital específico para que os professores interessados se candidatem.

Para a conclusão do processo com consequente obtenção do título de especialista, o professor residente deverá cumprir todos os requisitos previamente sinalizados pelo programa, quais sejam: frequentar e cumprir as atividades designadas, fazer relatório semestral sobre as atividades realizadas, elaborar memorial sobre a experiência profissional no PRD e elaborar um produto acadêmico-pedagógico sob orientação e assessoria do professor supervisor. Havendo cumprido satisfatoriamente os pré-requisitos para a conclusão do curso, o residente receberá o certificado de "Especialista em docência do ensino básico, com ênfase em... (completar com a área de atuação e formação do residente)”.

Entende-se que essas iniciativas, dentre as primeiras de que tomou-se conhecimento no Brasil, vêm se apresentando nesse caminho, como avanço, na tentativa de dar suporte a professores em início de carreira. Entretanto, se reconhece a necessidade de que outras ações sejam desenvolvidas ou algumas ampliadas (se for o caso) de modo a atingir um contingente maior de professores. Sabe-se também que essas medidas precisam ser equacionadas juntamente com outras políticas que se relacionem às condições de trabalho dos professores, no sentido mais amplo do termo, bem como com outras de caráter social e econômico, para que não corramos o risco de responsabilizar unicamente os professores e sua formação pelos resultados dos alunos. Isso é, políticas de formação e desenvolvimento profissional, quaisquer que sejam elas, isoladamente, não são suficientes para dar conta da complexidade das situações de aprendizagem e trabalho vividas por alunos e professores.

Vale ainda destacar que, no conjunto de ações formativas que vêm sendo desenvolvidas no âmbito da Política Nacional de Formação dos Profissionais do Magistério da Educação Básica, está o Programa de Bolsa de Iniciação à Docência (PIBID). Embora ele não esteja inserido no âmbito dos programas de inserção à docência, tais como considerados na literatura, isto é, aqueles destinados aos professores já licenciados e em seus primeiros anos de atuação nas escolas como docentes, ele é uma iniciativa que, como foi visto, vem se apresentando como possibilidade na aproximação e identificação do futuro docente com seu campo de trabalho e favorecendo a aproximação entre universidade e escola, além de propiciar oportunidades de desenvolvimento profissional ainda no período de formação inicial.

A concentração dos estudos sobre professores iniciantes no estado de São Paulo sinaliza a relevante contribuição de universidades desse estado para a elucidação do trabalho docente na fase de iniciação e aponta para a necessidade de que maiores investimentos em pesquisas sobre o assunto sejam realizados também em outros lugares, com outros docentes iniciantes, em outras realidades, uma vez que não se pode falar de modo generalizado sobre dificuldades, socialização, saberes profissionais, programas de iniciação, práticas de iniciantes, entre outros assuntos, sem pesquisas que forneçam subsídios para assim fazê-lo. 
Um aspecto que se mostrou frágil e que precisa ser considerado nas pesquisas sobre a fase de iniciação é o trabalho também com docentes de escolas privadas. Com condições de trabalho e de vida tão diversificadas, não é possível falar generalizadamente sobre professores principiantes. Ter como prioridade e defender a escola pública não significa que se possa ignorar o contingente que está trabalhando fora dela, ou ainda que conjuga o trabalho em setores públicos e privados.

Os achados desta revisão de literatura reiteram as sínteses anteriores no sentido de mostrar a importância da continuidade dos investimentos em pesquisas sobre o início da docência e se diferenciam e/ou acrescentam a elas outras constatações, como mostramos ao longo texto. Embora a ênfase na temática seja crescente, nota-se que é preciso ampliar os estudos na área, haja vista que, em quatro anos de reuniões do principal encontro de apresentação de pesquisas no Brasil, a ANPED, foram encontrados apenas quatro trabalhos sobre o tema. O desafio permanece.

\section{Referências}

COLÉGIO PEDRO II (2011). Programa de residência docente no Colégio Pedro II. Rio de Janeiro. Disponível em: <http://www. cp2.g12.br/UAs/dppg/PRD/pdf/Conheca\%20 o\%20programa.pdf $>$. Acesso em: 20 jul. 2011.

CUNHA, M. I. da. O campo da iniciação à docência universitária como um desafio. 2010. Disponível em: <http://www.anped.org. br>. Acesso em: 12 abr. 2012.

GATTI, B. A. BARRETTO, E. S. de Sá e ANDRÉ, M. E. D. de A. Políticas docentes no Brasil: um estado da arte. Brasília: Unesco, 2011.
HUBERMAN, M. O ciclo de vida profissional dos professores. NÖVOA, A. (Org) Vidas de professores. Porto: Porto Editora, 1992.

ISAIA, S. M. de A.; MACIEL, A. M. da R.; BOLZAN, D. P. V. Educação superior: a entrada na docência universitária. 2010. Disponível em: <http://www.anped.org.br>. Acesso em: 12 abr. 2012.

LIMA, E. F. de. A construção do início da docência: reflexões a partir de pesquisas brasileiras. Rev. do Centro de Educação, Universidade Federal de Santa Maria, v. 29, n. 2, 2004.

MARCELO, C. Formação de professores para uma mudança educativa. Porto: Porto Editora, 1999.

Desenvolvimento profissional docente : passado e futuro. Sísifo. Rev. de Ciências da Educação, 8, 7-22, 2009.

. Políticas de inserción en la docencia: de eslabón perdido a puente para el desarrollo profesional docente. Documentos PREAL, 52, 3-29, 2011.

MARIANO, A. L. S. A pesquisa sobre o professor iniciante e o processo de aprendizagem profissional: algumas características. 2006a. Disponível em: $<$ http://www.anped.org.br>. Acesso em: 12 abr. 2012.

. Aconstrução do início da docência: um olhar a partir das produções da ANPED e do ENDIPE. Dissertação (Mestrado em Educação). São Carlos, UFSCAR, 2006b.

MARIANO, A. L. S. Aprendendo a ser professor no início da carreira: um olhar a partir da ANPED. 2005. Disponível em: $<$ http://www.anped.org.br>. Acesso em: 12 abr. 2012. 
PAPI, S. Professoras iniciantes bemsucedidas: elementosdeseudesenvolvimento profissional. 2011. Disponível em: <http:// www.anped.org.br>. Acesso em: 12 abr. 2012.

PAPI, S. e MARTINS, P. As pesquisas sobre professores iniciantes: algumas aproximações. Educação em Revista. Belo Horizonte, v.26, n. 03, p. 39-56, dez/2010.

- Professores iniciantes: as pesquisas e suas bases teórico-metodológicas. Linhas Críticas, Brasília, v. 14, n. 27, p. 251-269, jul./dez. 2009.

RIBEIRO, M. T. de M.; AMBROSETTI, N. B.; TEIXEIRA, M. B. PIBID: uma proposta de iniciação à docência no curso de pedagogia. 2011. Disponível em: <http:// www.anped.org.br>. Acesso em: 12 abr. 2012.

VEENMAN, S. El proceso de llegar a ser profesor: um análisis de la formacción inicial. In: VILLA, A. (Coord.). Prespectivas y problemas de la funcción docente. Madrid: Narcea, 1988.

Enviado em: 30/09/2012

Aceito em: 26/10/2012 